\title{
Orthostatic intolerance predicts mild cognitive impairment: incidence of mild cognitive impairment and dementia from the Swedish general population cohort Good Aging in Skåne
}

This article was published in the following Dove Press journal:

Clinical Interventions in Aging

20 November 2014

Number of times this article has been viewed

\author{
Sölve Elmståhl \\ Elisabet Widerström \\ Division of Geriatric Medicine, \\ Department of Health Sciences, Lund \\ University, Skåne University Hospital, \\ Malmö, Sweden
}

Introduction: Contradictory results have been reported on the relationship between orthostatic hypotension $(\mathrm{OH})$ and mild cognitive impairment $(\mathrm{MCI})$.

Objective: To study the incidence of MCI and dementia and their relationship to $\mathrm{OH}$ and subclinical $\mathrm{OH}$ with orthostatic symptoms (orthostatic intolerance).

Study design and setting: This study used a prospective general population cohort design and was based on data from the Swedish Good Aging in Skåne study (GÅS-SNAC), they were studied 6 years after baseline of the present study, with the same study protocol at baseline and at follow-up. The study sample comprised 1,480 randomly invited subjects aged 60 to 93 years, and had a participation rate of $82 \%$ at follow-up. OH test included assessment of blood pressure and symptoms of $\mathrm{OH}$

Results: The 6-year incidence of MCI was $8 \%$, increasing from 12.1 to 40.5 per 1,000 personyears for men and 6.9 to 16.9 per 1,000 person-years for women aged 60 to $>80$ years. The corresponding 6-year incidence of dementia was $8 \%$. Orthostatic intolerance during uprising was related to risk for MCI at follow-up (odds ratio [OR] =1.84 [1.20-2.80][95\% CI]), adjusted for age and education independently of blood pressure during testing. After stratification for hypertension (HT), the corresponding age-adjusted OR for MCI in the non-HT group was $1.71(1.10-2.31)$ and 1.76 (1.11-2.13) in the HT group. Among controls, the proportion of those with $\mathrm{OH}$ was $16 \%$; those with MCI 24\%; and those with dementia 31\% (age-adjusted OR 1.93 [1.19-3.14]).

Conclusion: Not only $\mathrm{OH}$, but also symptoms of $\mathrm{OH}$, seem to be a risk factor for cognitive decline and should be considered in the management of blood pressure among the elderly population.

Keywords: orthostatic blood pressure, epidemiology, elderly

\section{Introduction}

Contradictory results have been reported on the relationship between orthostatic hypotension $(\mathrm{OH})$ and cognitive impairment. The large Atherosclerosis Risk in Communities Study (ARIC) reported no association between cognitive performance and $\mathrm{OH}$, adjusted for cardiovascular risk factors after a 6-year follow-up, similar to clinical studies on hypotensive syndromes in geriatric patients. ${ }^{1,2}$ Increased prevalence of $\mathrm{OH}$ was reported in a clinical study of subjects suffering from dementia, ${ }^{3}$ and elderly subjects attending memory clinics showed an association between impaired cognitive function and $\mathrm{OH}$, emphasizing the need for longitudinal studies to investigate the nature of this association. ${ }^{4}$ A 5-year longitudinal study in otherwise healthy elderly women reported low beta activity on electroencephalography 5 years later among those with $\mathrm{OH}$ in contrast to
Correspondence: Sölve Elmståh

Department of Health Sciences, Skåne

University Hospital and Lund University,

SE-205 02 Malmö, Sweden

Tel +46 4039 I 320

Fax +464039 I3 I3

Email solve.elmstahl@med.lu.se 
women without $\mathrm{OH}$ who remained dementia-free. ${ }^{5}$ A recent review by Perlmuter et al pointed out that few studies have specifically examined the effects of subclinical OH. ${ }^{6}$

Several factors might influence the incoherent findings between $\mathrm{OH}$ and cognitive decline.

Clinical $\mathrm{OH}$ is defined as a 20 or $10 \mathrm{mmHg}$ drop in systolic or diastolic peripheral blood pressure after rising from a supine to an upright position. Subclinical OH (orthostatic intolerance OI) 6 is defined as a systolic drop $<20 \mathrm{mmHg}$ or diastolic drop $<10 \mathrm{mmHg}$ with a variety of orthostatic symptoms, like dizziness, fatigue, and lightheadedness as a result of deteriorated cerebral autoregulation. ${ }^{7}$ Thus, changes in cerebral autoregulation at levels below the present $\mathrm{OH}$ definitions of peripheral blood pressure drop might induce OI, which has not been taken into account in studies using the present $\mathrm{OH}$ definition.

Another factor could be the modifying effect of hypertension. Hypertension is a risk factor for $\mathrm{OH}$ due to arterial stiffening, which, in turn, reduces the ability of cerebral autoregulation to compensate for blood pressure variation. ${ }^{8}$ When this ability declines, the intracerebral vessels are more unprotected from sudden lowering or rising of blood pressure, which are associated with disruptions in neurovascular coupling that could lead to cognitive decline. ${ }^{8}$ Further, hypotension has been recognized as a risk factor for cognitive decline or dementia, especially in subjects with $\mathrm{OH}$, since their blood pressure might fall below limits of autoregulation during orthostatic drops. ${ }^{9,10}$ Whether low blood pressure is a consequence or cause of incipient dementia is a question that remains to be solved. ${ }^{11}$ Furthermore, age-related changes in circadian rhythm with low blood pressure during the night and also dipping at night has been associated with lower cerebral blood flow and cognitive impairment. ${ }^{12}$

The concept of mild cognitive impairment (MCI) can be categorized into amnestic MCI (aMCI) and non-amnestic (single or multidomain) MCI (naMCI), depending on the cognitive domains affected. ${ }^{13}$ Asymptomatic $\mathrm{OH}$ has been correlated with cognitive decline and memory complaints among diabetes mellitus patients and associated with cardiovascular risk factors; ${ }^{6}$ however, few, if any, studies have examined the effect of symptomatic subclinical $\mathrm{OH}$ on cognition. Cognitive decline associated with $\mathrm{OH}$ most likely reflects the effect of impaired cerebral perfusion on end artery-supplied areas such as the hippocampus, which is known to play an important role in both short- and longterm memory and spatial ability. Decline in hippocampal size is known to predict conversion from MCI to dementia. ${ }^{14}$ In this study, we have chosen three-word recollection from the Mini-Mental State Examination (MMSE) ${ }^{15}$ as an indicator of memory and learning ability. MCI in this study could therefore be referred to as aMCI. $\mathrm{OH}$ is common in the elderly population. The prevalence of $\mathrm{OH}$ increases from about $15 \%$ to $30 \%$ in those aged 60 to 90 years of age and could be a contributory factor for MCI. ${ }^{7}$

Recent studies have indicated changes in incidence and prevalence of MCI and dementia. The Rotterdam Study reported decreased mortality from 1990 to 2000, but also a decreasing incidence of dementia, from 31 to 26 per 1,000 person-years (py), in the age range 80 to 89 years. ${ }^{16}$ A Swedish study with a follow-up of the Kungsholmen cohort noted constant dementia prevalence and reduced mortality, indicating a lower incidence. ${ }^{17}$ The US Health Retirement Study 1993-2002 reported a marginal reduction in MCI prevalence, which was partly explained by better education. ${ }^{18}$ These findings call for further longitudinal studies to compare whether changes in incidence of MCI and dementia in the general elderly population are taking place.

The aims of this study were to describe the incidence of MCI and dementia and, secondly, to explore relationships between $\mathrm{OH}$ and orthostatic symptoms (OI) and the risk of cognitive decline in a longitudinal 6-year follow-up study among the general elderly population.

\section{Methods}

This was a prospective cohort study based on data from the longitudinal general population study Good Aging in Skåne (GÅS-SNAC), part of the Swedish National Study on Aging and Care. ${ }^{19,20}$ The GÅS-SNAC population, which comprised 2,931 men and women (44\%/56\%, respectively) from nine age cohorts - 60, 66, 72, 78, 81, 84, 87, 90, and 93 years of age was randomized from five urban and rural municipalities and invited to participate by letter using the National Municipality Registry. Baseline examination was conducted between February 2001 and July 2004, with a participation rate of $60 \%$. At follow-up 6 years later (2007-2010) ( participation rate: $82 \%$ of survivors), 1,832 participants were reexamined, with 1,099 subjects lost to follow-up (710 deceased, nine moved out of county, and 380 nonparticipants). All subjects gave their informed consent prior to taking part in the study.

Exclusion criteria were the following conditions at baseline: MMSE score $<24 ;{ }^{15} \mathrm{MCI}$ or dementia (definitions below); previous stroke; myocardial infarction or angina pectoris; and inability to perform an $\mathrm{OH}$ test. An additional 23 participants with incomplete cognitive tests at baseline or follow-up examination were excluded, leaving a total of 1,480 participants fulfilling the study criteria. 
Dementia was defined according to the Diagnostic and Statistical Manual of Mental Disorders, Fourth Edition (DSM-IV) criteria, ${ }^{21}$ based on clinical examination, medical records, and proxy information from spouses/relatives and ward staff. The categorization of all other diseases was based on the International Statistical Classification of Diseases and Related Health Problems (ICD)-10 after medical examination. ${ }^{22}$ Stroke included cerebral infarction, hemorrhage, and transient ischemic attack. The project physician had access to all inpatient medical records from the National Medical database covering all hospitals in southern Sweden. Outpatient medical records were retrieved from general practitioners. Inpatient medical diagnoses were also retrieved from the Swedish National Inpatient Register covering all visits in Sweden until 1987 using the specific and individual Swedish civic number. Medication was categorized according to the Anatomical Therapeutic Chemical classification. ${ }^{23}$ Antihypertensive medication referred to current medication.

MCI was defined as the combination of cognitive complaint and cognitive decline evident from objective cognitive tasks in the absence of dementia. ${ }^{24}$ Cognitive complaint was assessed by the common self-reported scale by Crook et al, which contains six 5 -graded questions on memory functioning in daily functioning and the and the sum scores range from 7 to $35 .{ }^{25}$ The age-adjusted cut-off limit was set to the mean +1 standard deviation limit corresponded to a score of 28. Cognitive decline was defined as a score of 0 or 1 on the MMSE three-word later recall test. ${ }^{15}$ Since memory domain was the criteria for cognitive decline, our definition of MCI could be referred to as aMCI. Dementia or an MMSE score below 24 at follow-up were not included in MCI. Impaired activities of daily living (ADL) was not considered an exclusion criterion. However, $88 \%$ were independent in instrumental ADL, including shopping, transportation, cooking, and cleaning (definition below), and $86 \%$ were independent in personal ADL, including six activity functions: mobility, dressing, eating, bowel function, bladder function, and bathing.

Subjective memory loss was defined as a score of $>28$ on the Crook scale in the absence of objective memory loss, dementia, or an MMSE score below 24. Objective memory loss was defined as a score of 0 or 1 on the MMSE three-word later recall test in the absence of subjective memory loss, dementia, or an MMSE score below 24. Thus, at follow-up, the MCI, dementia, subjective memory loss, objective memory loss, and control groups were mutually exclusive.

The study procedures included the same study protocol at baseline and follow-up, including a comprehensive medical examination by a physician with detailed medical history, diagnoses, medication, assessments of physical and cognitive tests by trained registered nurses, and self-reported questionnaires. Information was requested regarding cognition and ADL performance from spouses and from ward staff for participants in sheltered living. Visits at home or in sheltered living were offered if the participant was unable to come to the research center. Descriptive data of the population are presented in Table 1.

Hypertension was defined as $>140 / 90 \mathrm{mmHg}$ or current antihypertensive drug treatment. Systolic (SBP) and diastolic blood pressure (DBP) were measured to the nearest $2 \mathrm{mmHg}$ with an appropriate size-adjusted cuff around the right arm (with the subject in a sitting position) three consecutive times using a mercury sphygmomanometer, and a mean blood pressure value was calculated.

For the $\mathrm{OH}$ test, participants rested in the supine position for 10 minutes before starting the test. Blood pressure and pulse were assessed immediately after the rise from the supine to a standing position and after $1,3,5$, and 10 minutes of standing without external help. $\mathrm{OH}$ was defined as a fall in SBP of greater than $20 \mathrm{mmHg}$ and/or a fall in DBP of greater than $10 \mathrm{mmHg}$ after 1 to 10 minutes' standing and a fall in DBP of greater than 40 and $20 \mathrm{mmHg}$ SBP/DBP immediately upon standing up. Recovery of SBP was defined as the quotient of the highest recorded SBP after the stand and SBP at rest. Maximal SBP and DBP fall during the 10-minute stand was defined as the difference between baseline and the lowest value after the stand. Participants were asked whether they experienced symptoms of autonomic failure associated with $\mathrm{OH}$ during the test and about occurrence of the same symptoms during the preceding 12 months when rising to a standing position according to a predefined protocol of listed signs and symptoms. The following 12 signs and symptoms of OI in relation to standing were asked about: dizziness, fatigue, blackouts, nausea, instability, ringing in the ears, vertigo, lightheadedness, headache, syncope, confusion, and sweating. Subjects reporting any of these symptoms in the preceding year were categorized as "previous OI" and those who experienced symptoms or signs during the $\mathrm{OH}$ test were categorized as "present OI".

Subjects were categorized according to their smoking habits as present smokers (regular/occasional smoking), former smokers, and nonsmokers. Physical activity was divided into two categories, with low-to-medium activity referring to a sedentary lifestyle or light activity for 2-4 hours weekly, and high activity referring to gardening, running, or other strenuous activities for $\geq 3$ hours weekly. Marital and cohabitation statuses were 
Table I Baseline descriptive statistics of mean values and proportions of $\mathrm{OH}$ test parameters and background factors for controls and participants with $\mathrm{MCl}$, dementia, and objective and subjective memory loss at 6-year follow-up of the general elderly Swedish population of GÅS-SNAC $(n=I, 480)$

\begin{tabular}{|c|c|c|c|c|c|c|}
\hline & Controls & $\begin{array}{l}\text { Objective } \\
\text { memory loss }\end{array}$ & $\begin{array}{l}\text { Subjective } \\
\text { memory loss }\end{array}$ & $\mathrm{MCl}$ & Dementia & All participants \\
\hline Participants (n/\%) & $697 / 47$ & $38 I / 26$ & $158 / 1 \mid$ & $123 / 8$ & $121 / 8$ & $1,480 / 100$ \\
\hline Valid $\mathrm{OH}$ test & 686 & 375 & 156 & 123 & 119 & 1,459 \\
\hline Men/women (\%) & $44 / 56$ & $53 / 47$ & $32 / 68$ & $52 / 48$ & $42 / 58$ & $46 / 54$ \\
\hline Age (years) & 65.6 & 67.6 & 70.1 & 71.7 & 76.2 & 68.0 \\
\hline High school/university (\%) & $32 / 29$ & $27 / 18$ & $17 / 24$ & $24 / 15$ & $27 / 12$ & $29 / 23$ \\
\hline Hypertensive $(>140 / 90)$ or antihypertensive treatment $(\%)$ & 60 & 67 & 65 & 67 & 73 & 64 \\
\hline Hypertensive at baseline (mean of 3 BP) (\%) & 55 & 61 & 56 & 59 & 68 & 59 \\
\hline Antihypertensive treatment (\%) & 21 & 24 & 27 & 25 & 33 & 23 \\
\hline Diabetes type I/2 (\%) & $0.3 / 4.6$ & $0.5 / 5.8$ & $0 / 4.4$ & $0.8 / 4.9$ & I.7/10.7 & $0.5 / 5.4$ \\
\hline Treatment for hyperlipidemia (\%) & 13 & 18 & 16 & 15 & 15 & 15 \\
\hline Physical inactivity (\%) & 11 & 12 & 11 & 17 & 25 & 13 \\
\hline Present smoker (\%) & 13 & 17 & 11 & 8 & 15 & 13 \\
\hline Past or present smoker (\%) & 62 & 57 & 60 & 50 & 49 & 58 \\
\hline Born abroad (\%) & 9 & 7 & 9 & 9 & 10 & 9 \\
\hline Single or living alone (\%) & 28 & 35 & 50 & 30 & 45 & 30 \\
\hline SBP resting $(\mathrm{mmHg})($ mean; SD) & $142 ; 19$ & |46; 21 & $|44 ; 2|$ & |49; 2 | & $149 ; 20$ & $146 ; 22$ \\
\hline DBP resting $(\mathrm{mmHg})($ mean; SD) & $82 ; 9.2$ & $82 ; 9.7$ & $80 ; 10.5$ & $81 ; 9.8$ & $79 ; 10.0$ & $83 ; 10.6$ \\
\hline Heart rate resting (mean; SD) & $67 ; 11$ & $66 ; 10$ & $68 ; 10$ & $66 ; 13$ & $68 ; 11$ & $67 ; 11$ \\
\hline Max difference SBP supine - upright 10 minutes (mean; SD) & $10 ; 11$ & $11 ; 10$ & $11 ; 12$ & $12 ; 11$ & $15 ; 15$ & $\mathrm{II} ; \mathrm{II}$ \\
\hline Max difference DBP supine - upright 10 minutes (mean; SD) & $2 ; 6$ & $2 ; 6$ & $3 ; 6$ & $3 ; 6$ & $4 ; 7$ & $2 ; 6$ \\
\hline Max heart rate during $\mathrm{OH}$ test (mean; SD) & $78 ; 13$ & $77 ; 12$ & $78 ; 11$ & $77 ; 13$ & $79 ; 13$ & $78 ; 13$ \\
\hline Change in heart rate during $\mathrm{OH}$ test (mean; SD) & $12 ; 8$ & $12 ; 7$ & $12 ; 11$ & $12 ; 10$ & $12 ; 7$ & $12 ; 8$ \\
\hline $\mathrm{OH}$ (SBP falls $>20 \mathrm{mmHg} / \mathrm{DBP}>10 \mathrm{mmHg}$ ) (\%) & 17 & 17 & 8 & 24 & 34 & 19 \\
\hline Systolic OH falls $>20 \mathrm{mmHg}(\%)$ & 9 & 10 & 12 & 15 & 23 & 11 \\
\hline Diastolic $\mathrm{OH}$ falls > $10 \mathrm{mmHg}(\%)$ & 5 & 6 & 8 & 8 & 10 & 6 \\
\hline Previous or present orthostatic intolerance (\%) & 25 & 28 & 35 & 41 & 25 & 28 \\
\hline Previous orthostatic intolerance (\%) & 22 & 27 & 31 & 40 & 23 & 26 \\
\hline Present orthostatic intolerance (\%) & 6 & 5 & 8 & 9 & 8 & 7 \\
\hline Subjective memory loss at baseline (\%) & 1.6 & 2.4 & 15.8 & 6.5 & 5.0 & $\mathrm{II}$ \\
\hline Objective memory loss at baseline (\%) & 19.1 & 44.6 & 24.1 & 47.2 & 53.7 & 25.7 \\
\hline
\end{tabular}

Abbreviations: DBP, diastolic blood pressure; GÅS-SNAC, Good Aging in Skåne; max, maximum; MCl, mild cognitive impairment; OH, orthostatic hypotension; SBP, systolic blood pressure; SD, standard deviation.

categorized as either living alone or living in a relationship. Education was categorized in four groups: elementary school, secondary school, high school, and university level.

Diabetes was defined as either diabetes mellitus type 1 or type 2 according to ICD-10 and based on information from medical records. ADL was assessed through selfreport according to Åsberg and Sonn's revised ADL scale, which assesses four instrumental ADL (cleaning, grocery shopping, transportation, and cooking) and six activities of personal daily living, including bathing, mobility, and eating. ${ }^{26}$ Independence in ADL was defined as independence in instrumental ADL and activities of personal daily living. ${ }^{26}$ Depressive mood was assessed by means of the Comprehensive Psychopathological Rating Scale (CPRS), part of the Montgomery-Åsberg Depression Rating Scale (MADRS) comprising 20 items scored from 1 to 60 with a score of $>20$ indicating depressive mood. ${ }^{27}$
SPSS version 20 was used for statistical analysis. Presence of $\mathrm{OH}$ at baseline was related to the risk of incident dementia, MCI, only subjective memory complaints, or only objective memory loss at 6-year follow-up and expressed as odds ratios (ORs) with 95\% confidence intervals (CIs) in separate logistic regression analyses adjusted for age and education. The same analyses were performed stratified for hypertension or antihypertensive drug treatment. A linear regression model, adjusted for age (data not shown) analyzed the relationship between MCI and maximal blood pressure fall. Seventeen participants lacked information on resting blood pressure in the $\mathrm{OH}$ test and the mean value of three sitting blood pressure assessments were imputed. The chi-square test was used to test differences in proportion between the groups. The rationale for excluding stroke and cardiovascular conditions at baseline was that both are potential confounding factors that could introduce false risk associations. 
The Regional Ethics Committee at Lund University, Lund, Sweden approved the study. All subjects provided written consent for participation in the study.

\section{Results}

The mean age of the study sample was 68 (standard deviation 8.5 ) years. The sample comprised $44 \%$ men and $56 \%$ women, and $53 \%$ of all participants presented some degree of cognitive deficit at the 6-year follow-up (Table 1).

The incidence of MCI during the 6-year follow-up was $8 \%$ of the total study population, or $14.2 / 1,000$ py (Table 2 ), distributed among age groups as follows: $12.1 / 1,000$ py and 6.9/1,000 py for men and women aged 60 to 69 years, respectively, to $40.5 / 1,000$ py for men and $16.9 / 1,000$ py for women aged $>80$ years.
The incidence of dementia was $8 \%$ (13.9/1,000 py), distributed as 5.7/1,000 py and 6.2/1,000 py for men and women aged 60 to 69 years, respectively, and increasing to 38.2/1,000 py for men and 46.2/1,000 py for women aged $>80$ years. The occurrence of any type of cognitive impairment during this 6-year period was $90.2 / 1,000$ py. The group with incident dementia had a higher proportion of hypertension/treatment for hypertension (73\%) at baseline compared to controls $(60 \%)$.

The proportion of $\mathrm{OH}$ was $18 \%$ in the total sample, with $16 \%$ among controls compared to $24 \%$ in the MCI group $(P=0.413)$ and $31 \%$ in the dementia group $(P=0.008$; $\mathrm{OR}=1.93$ [95\% CI: 1.19-3.14]) after age adjustments. The prevalence of $\mathrm{OH}$ was $14 \%$ among those aged 60 to 69 years, $23 \%$ among those aged 70 to 79 years, and $28 \%$ among subjects $>80$ years in the total study population.

Table 2 Six-year incidence of $\mathrm{MCl}$ and dementia at follow-up and prevalence of $\mathrm{OH}$ at baseline in the general elderly Swedish population of GÅS-SNAC $(n=I, 480)$

\begin{tabular}{|c|c|c|c|c|c|c|}
\hline & $\begin{array}{l}\text { Number } \\
\text { of persons (\%) }\end{array}$ & $\begin{array}{l}\text { Mean } \\
\text { py }\end{array}$ & $\begin{array}{l}\text { Total } \\
\text { py }\end{array}$ & $\begin{array}{l}\text { 6-year } \\
\text { incidence/I,000 py }\end{array}$ & $\begin{array}{l}\text { OH at } \\
\text { baseline } \\
\text { (\%) }\end{array}$ & $\begin{array}{l}\text { All persons } \\
(\%)\end{array}$ \\
\hline Total study sample & $\mathrm{I}, 480^{\mathrm{a}}$ & 5.86 & 8,681 & & 18 & 100 \\
\hline Controls (all) & 697 & 5.87 & 4,092 & - & 16 & 47 \\
\hline Men (\%)/women (\%) & $309(44) / 388(56)$ & $5.87 / 5.87$ & $\mathrm{I}, 8 \mid 4 / 2,278$ & - & & \\
\hline $60-69$ years $(\%)$ & $253(47) / 290(53)$ & $5.86 / 5.86$ & $\mathrm{I}, 484 / \mathrm{I}, 699$ & - & & \\
\hline $70-79$ years $(\%)$ & $40(42) / 56(58)$ & $5.90 / 5.90$ & $236 / 330$ & - & & \\
\hline $80+$ years $(\%)$ & $16(28) / 42(72)$ & $5.91 / 5.93$ & $95 / 249$ & - & & \\
\hline Objective memory loss (all) & 381 & 5.85 & 2,229 & 43.9 & 16 & 26 \\
\hline Men (\%)/women (\%) & $20 I(53) / 180(47)$ & $5.83 / 5.86$ & $\mathrm{I}, 172 / \mathrm{I}, 055$ & $50.9 / 31.4$ & & \\
\hline $60-69$ years $(\%)$ & I $45(57) / 108(43)$ & $5.83 / 5.86$ & $845 / 633$ & $51.7 / 37.4$ & & \\
\hline $70-79$ years $(\%)$ & $37(47) / 4 \mid(53)$ & $5.83 / 5.84$ & $216 / 239$ & $52.8 / 42.9$ & & \\
\hline $80+$ years $(\%)$ & $19(38) / 31(62)$ & $5.86 / 5.90$ & $111 / 183$ & $42.7 / 35.1$ & & \\
\hline Subjective memory loss (all) & 158 & 5.87 & 928 & 18.2 & 19 & 11 \\
\hline Men (\%)/women (\%) & $51(32) / 107(68)$ & $5.83 / 5.89$ & $297 / 630$ & $12.9 / 18.7$ & & \\
\hline 60-69 years (\%) & $32(36) / 57(64)$ & $5.83 / 5.82$ & $187 / 332$ & $11.4 / 19.7$ & & \\
\hline 70-79 years (\%) & $13(32) / 28(68)$ & $5.93 / 6.00$ & $77 / 168$ & $18.6 / 29.3$ & & \\
\hline $80+$ years $(\%)$ & $6(21) / 22(79)$ & $5.62 / 5.95$ & $34 /|3|$ & I3.5/24.9 & & \\
\hline MCl (all) & 123 & 5.82 & 716 & 14.2 & 24 & 8 \\
\hline Men (\%)/women (\%) & $64(52) / 59(48)$ & $5.74 / 5.90$ & $367 / 348$ & $16.2 / 10.3$ & & \\
\hline $60-69$ years $(\%)$ & $34(63) / 20(37)$ & $5.80 / 5.92$ & $197 / 118$ & $12.1 / 6.9$ & & \\
\hline 70-79 years (\%) & $12(33) / 24(67)$ & $5.62 / 5.80$ & $67 / 139$ & $17.1 / 25.1$ & & \\
\hline $80+$ years $(\%)$ & $18(55) / 15(45)$ & $5.71 / 6.03$ & $|03 / 9|$ & $40.5 / 16.9$ & & \\
\hline Dementia (all) & 121 & 5.94 & 719 & 13.9 & 31 & 8 \\
\hline Men (\%)/women (\%) & $5 \mathrm{I}(42) / 70(58)$ & $5.92 / 5.96$ & $302 / 417$ & $12.9 / 12.2$ & & \\
\hline $60-69$ years $(\%)$ & $16(47) / 18(53)$ & $5.94 / 5.98$ & $95 / 108$ & $5.7 / 6.2$ & & \\
\hline 70-79 years (\%) & I8 (58)/ / 3 (42) & $5.80 / 6.06$ & $104 / 79$ & $25.7 / 13.6$ & & \\
\hline $80+$ years $(\%)$ & $17(30) / 39(70)$ & $6.02 / 5.91$ & $102.3 / 230.5$ & $38.2 / 46.2$ & & \\
\hline $\begin{array}{l}\text { Any form of cognitive } \\
\text { impairment (all) }\end{array}$ & 783 & 5.86 & 4,588 & 90.2 & 20 & 53 \\
\hline Men (\%)/women (\%) & $367(47) / 416(53)$ & $5.82 / 5.89$ & $2,136 / 2,450$ & $92.8 / 72.6$ & & \\
\hline 60-69 years (\%) & $227(53) / 203(47)$ & $5.83 / 5.87$ & $1,323 / 1,192$ & $80.9 / 70.3$ & & \\
\hline 70-79 years (\%) & $80(43) / / 06(57)$ & $5.81 / 5.90$ & $465 / 625$ & $1|4.2 / 1| 1.0$ & & \\
\hline $80+$ years $(\%)$ & $60(36) / 107(64)$ & $5.83 / 5.93$ & $350 / 634$ & $135.0 / 121.0$ & & \\
\hline
\end{tabular}

Note: an the total sample, $\mathrm{OH}$ tests were missing in 21 persons.

Abbreviations: GÅS-SNAC, Good Aging in Skåne; $\mathrm{MCl}$, mild cognitive impairment; OH, orthostatic hypotension; py, person-years. 
Table 3 Comparisons of baseline mean values, proportions of $\mathrm{OH}$ test parameters, and crude and age-adjusted ORs for groups with $\mathrm{MCl}$, dementia, and objective and subjective memory loss at 6-year follow-up of the general elderly Swedish population of GÅS-SNAC $(n=I, 480)$

\begin{tabular}{|c|c|c|c|c|}
\hline & $\begin{array}{l}\text { Controls versus } \\
\text { objective memory loss }\end{array}$ & $\begin{array}{l}\text { Controls versus } \\
\text { subjective memory loss }\end{array}$ & Controls versus $\mathrm{MCl}$ & $\begin{array}{l}\text { Controls versus } \\
\text { dementia }\end{array}$ \\
\hline SBP, resting $(P)$ & 0.037 & $0.81 \mathrm{I}$ & 0.064 & 0.435 \\
\hline DBP, resting $(P)$ & 0.715 & 0.175 & 0.948 & 0.316 \\
\hline $\begin{array}{l}\text { Quotient SBP supine } / 5 \text { minutes after } \\
\text { uprising }(P)\end{array}$ & 0.208 & 0.205 & 0.327 & 0.598 \\
\hline SBP orthostatic diff $\max (P)$ & 0.280 & 0.777 & 0.217 & 0.004 \\
\hline DBP orthostatic diff $\max (P)$ & 0.446 & 0.600 & 0.182 & 0.036 \\
\hline Pulse maximum $(P)$ & 0.493 & 0.625 & 0.107 & 0.843 \\
\hline Pulse difference $(P)$ & 0.537 & 0.365 & 0.963 & 0.958 \\
\hline \multicolumn{5}{|l|}{$\mathrm{OH}$, systolic or diastolic } \\
\hline OR $(95 \% \mathrm{Cl})$ & $1.03(0.74-1.44)$ & $1.27(0.82-1.96)$ & $1.59(1.00-2.50)$ & $2.49(1.62-3.82)$ \\
\hline OR, age-adjusted $(95 \% \mathrm{Cl})$ & $0.95(0.68-1.33)$ & $1.07(0.68-1.69)$ & $1.23(0.75-2.00)$ & $1.93(1.19-3.14)$ \\
\hline \multicolumn{5}{|l|}{ Systolic $\mathrm{OH}$} \\
\hline OR $(95 \% \mathrm{Cl})$ & $1.05(0.69-1.60)$ & $1.33(0.78-2.30)$ & $1.74(1.00-3.03)$ & $2.83(1.72-4.67)$ \\
\hline OR, age-adjusted ( $95 \% \mathrm{Cl})$ & $0.99(0.64-1.5 \mathrm{I})$ & $1.12(0.64-1.96)$ & $1.41(0.79-2.53)$ & $2.18(1.24-3.84)$ \\
\hline \multicolumn{5}{|l|}{ Diastolic $\mathrm{OH}$} \\
\hline OR $(95 \% \mathrm{Cl})$ & $1.18(0.69-2.03)$ & $1.64(0.85-3.18)$ & $1.6(0.77-3.32)$ & $2.03(1.02-4.02)$ \\
\hline OR, age-adjusted $(95 \% \mathrm{Cl})$ & $1.61(0.61-1.83)$ & $1.32(0.67-2.60)$ & $1.19(0.55-2.55)$ & $1.35(0.62-2.93)$ \\
\hline \multicolumn{5}{|l|}{ Previous or present $\mathrm{Ol}$} \\
\hline OR $(95 \% \mathrm{Cl})$ & I.II (0.84-I.47) & $1.55(1.07-2.25)$ & $2.07(1.39-3.08)$ & $0.98(0.62-1.53)$ \\
\hline OR, age-adjusted $(95 \% \mathrm{Cl})$ & $1.10(0.83-1.47)$ & $1.55(1.06-2.27)$ & $2.01(1.33-3.05)$ & $0.90(0.55-1.50)$ \\
\hline \multicolumn{5}{|l|}{ Previous symptoms of $\mathrm{Ol}$} \\
\hline OR $(95 \% \mathrm{Cl})$ & $1.26(0.94-1.68)$ & $1.58(1.08-2.32)$ & $2.31(1.54-3.45)$ & $1.01(0.64-1.61)$ \\
\hline OR, age-adjusted $(95 \% \mathrm{Cl})$ & $1.26(0.94-1.68)$ & $1.62(1.10-2.40)$ & $2.34(1.53-3.58)$ & $0.99(0.59-1.66)$ \\
\hline \multicolumn{5}{|l|}{ Present symptoms of Ol } \\
\hline OR $(95 \% \mathrm{Cl})$ & $0.80(0.46-1.39)$ & $1.36(0.72-2.60)$ & $1.47(0.74-2.94)$ & $1.36(0.67-2.79)$ \\
\hline OR, age-adjusted $(95 \% \mathrm{Cl})$ & $0.76(0.43-1.33)$ & $1.22(0.63-2.36)$ & $1.26(0.6 \mathrm{I}-2.6 \mathrm{I})$ & $0.98(0.44-2.22)$ \\
\hline
\end{tabular}

Abbreviations: $\mathrm{Cl}$, confidence interval; DBP, diastolic blood pressure; GÅS-SNAC, Good Aging in Skåne; MCl, mild cognitive impairment; OH, orthostatic hypotension; OI, orthostatic intolerance; OR, odds ratio; orthostatic diff max, maximum difference during $\mathrm{OH}$ testing; SBP, systolic blood pressure.

Table 3 presents the relationship between systolic or diastolic $\mathrm{OH}$ at baseline and $\mathrm{MCI}$ and dementia 6 years later $(\mathrm{OR}=1.59[95 \% \mathrm{CI}: 1.00-2.50]$ and $\mathrm{OR}=2.49[95 \% \mathrm{CI}$ : 1.62-3.82], respectively). Participants with OI, irrespective of $\mathrm{OH}$ drops in blood pressure during $\mathrm{OH}$ testing, had higher age-adjusted risk for incident $\mathrm{MCI} 6$ years later $(\mathrm{OR}=2.07$ [95\% CI: 1.39-3.08]) and also higher age-adjusted risk for subjective memory loss ( $\mathrm{OR}=1.55$ [95\% CI: 1.07-2.25]).

Of those 283 participants with $\mathrm{OH}$, the proportion of $\mathrm{OH}$ occurring only during the last 10 minutes of testing was $3.2 \%$ for diastolic $\mathrm{OH}(3 / 94)$ and $6.9 \%$ (17/247) for systolic $\mathrm{OH}$, and, overall, $5.9 \%$ of all the 283 identified $\mathrm{OH}$ cases was captured only at the 10-minute assessment. The significant relationship between previous and present $\mathrm{OI}$ and $\mathrm{MCI}$ was $\mathrm{OR}=1.84(95 \% \mathrm{CI}: 1.20-2.80)$ and the relationship between previous and present OI and subjective memory loss was $\mathrm{OR}=1.50$ (95\% CI: 1.02-2.20). The corresponding association between only previous OI and MCI was OR $=2.12(95 \%$ CI: $1.38-3.26)$ and, between OI and subjective memory loss, OR $=1.54$ (95\% CI: 1.04-2.28).
Age-adjusted ordinal regression analyses stratified for hypertension or hypertensive drug treatment showed the same significant pattern for OI at baseline as a predictor for developing MCI 6 years later independently of hypertension or treatment for hypertension. In the non-hypertensive group, the age-adjusted OR for present or previous OI at baseline and risk for incident MCI at 6-year follow-up, irrespective of blood pressure fall, was 1.71 (95\% CI: 1.10-2.31), compared to $\mathrm{OR}=1.76$ (95\% CI: 1.11-2.13) for the hypertensive group. The corresponding OR for previous OI only and MCI was 1.79 (95\% CI: 1.18-2.41) in the non-hypertensive group, compared to 2.00 (95\% CI: 1.40-2.61) for the hypertensive group. No associations were noted for incident dementia and OI after stratification for hypertension.

The combination of hypertension at baseline and incident MCI respectively incident dementia was associated to a higher proportion of $\mathrm{OH}$. Either systolic or diastolic $\mathrm{OH}$ during the test were noted in $37 \%$ of hypertensive incident $\mathrm{MCI}$ and $42 \%$ incident dementia cases. Corresponding proportions of $\mathrm{OH}$ in the non-hypertensive groups of $\mathrm{MCI}$ and 
dementia were $9 \%$ and $22 \%$. Recovery of SBP and changes of pulse during the $\mathrm{OH}$ test were not related to cognitive impairment or dementia (data not shown). Independence in ADL, such as shopping, transportation, cooking, or handling cleaning of their own house, was reported at baseline by $90 \%$ of the control group compared to $88 \%$ for the incident MCI group and $69 \%$ of the incident dementia group. Forty-two subjects had a CPRS score $>11$, indicating depressive mood at follow-up and distributed as follows: 15 subjects in the control group, eight in the group with objective memory loss, seven in the dementia group, six in the group with subjective memory loss, and six in the MCI group. Differences were not significant between groups. The proportions of those with diabetes and hypertension did not differ between the MCI and control groups, but were significantly higher among the dementia group than the controls (Table 1).

\section{Discussion}

The incidence of MCI in this cohort of the elderly general population investigated between 2001 and 2010 was $14.2 / 1,000$ py during a 6-year period (baseline took three years to perform during the years 2001 to 2004; the 6-year follow-up was performed during 2007 to 2010) increasing from 12.1 to 40.5 per 1,000 py among men and from 6.9 to 16.9 per 1,000 py among women from 60 to 90 years of age. Another finding was that $\mathrm{OH}$ is related to the development of dementia and cognitive decline, and that OI with symptoms of $\mathrm{OH}$, irrespective of drop in blood pressure, is related to incidence of MCI and subjective memory loss after adjustment for age and education. The incidence of objective memory loss seems to decline with age, but this is explained by a migration from this group to the MCI or dementia groups, in which the incidence rates increased with age.

Previous cross-sectional studies have reported an association between $\mathrm{OH}$ and cognitive decline..$^{4,6,12,28}$ A longitudinal study on $\mathrm{OH}$ and development of electroencephalography changes in previously healthy women indicated causality between $\mathrm{OH}$ and reduced cerebral blood flow, which in turn could lead to cerebral damage. ${ }^{5}$ To our knowledge, this is the first study showing the relationships between $\mathrm{OI}$ and incident MCI and between OI and subjective memory loss as possible early indicators of cerebral damage, without fulfilling the $\mathrm{OH}$ blood pressure criteria. The cause of $\mathrm{OI}$ is unknown, but may be related to abnormalities in the autonomic regulation of cardiovascular function. The cognitive decline suggests a deterioration of cerebral autoregulation over time. Several possible physiological mechanisms could explain the association between blood pressure regulation and cognition.
Collins et al found that parasympathetic dysfunction was more than five times more common among subjects with MCI compared to controls. ${ }^{29}$ They presented the hypothesis that this may be explained by early neuroanatomical and neurochemical changes caused by Alzheimer's disease. This may accelerate cognitive decline via proinflammatory mechanisms and/or hypotension-induced cerebral hypoperfusion. ${ }^{29}$ This would support that the findings related to aMCI are more sensitive predictors of early Alzheimer's disease than those of naMCI.

Another plausible cause could be age-related increased cerebral susceptibility to $\mathrm{OH}$ and blood pressure drops in parallel with a higher proportion of elderly subjects on antihypertensive drug treatment. Circadian blood pressure rhythms diminish with age as well as the normal nocturnal dipping noted in middle age. Nocturnal dipping is a normal finding in middle age but instead at high ages it has turned out to be risk factor for cognitive decline defined by cerebral blood flow and cognitive tests in longitudinal studies of subjects aged 80 years and above. ${ }^{12,30}$ This phenomenon is most likely related to prolonged periods of cerebral hypoxia. ${ }^{30} \mathrm{~A}$ previous study reported that SBP but not DBP changes during a stand test was related to OI, supporting findings from this study. ${ }^{31}$ This finding is in line with studies showing that SBP but not DBP changes (decline) during tilting correlate with reduced white matter cerebral blood flow in anterior and posterior brain regions among $\mathrm{OH}$ patients. ${ }^{32}$ Whereas DBP tends to drop with increasing age, SBP continues to increase with age regardless of the initial level in early to middle adulthood. The long-term impact of elevated midlife SBP on reduced cognitive performance has been reported in longitudinal studies. ${ }^{33,34}$

We have previously reported that cerebral blood flow in white matter is correlated with SBP, in contrast with DBP, and that SBP was lower among subjects with dementia compared to controls. ${ }^{35}$ This study shows an age-adjusted risk of orthostatic symtpoms in realtion to incident $\mathrm{MCI}$ and subjective memeory loss independent of peripheral blood pressure using regular brachial sphygmomanometers. These findings raise some questions concerning methods and definition of $\mathrm{OH}$. In this study, assessment of peripheral blood pressure after tilting to standing position was assessed in minute intervals. It is possible that continuous assessment might have detected a rapid blood pressure drop that occurred between the assessments. We chose to measure blood pressure at 1, 3, 5, and 10 minutes after changing from a supine to an upright position during the $\mathrm{OH}$ test. This is a longer time frame than in many other studies. ${ }^{36}$ The most common method is to measure blood pressure at 1 and 3 minutes, and 
sometimes also at 5 minutes. Of the 283 cases with $\mathrm{OH}$ in this study, 5.9\% occurred only after 10 minutes. We might have captured more subjects with $\mathrm{OH}$ than other studies, even though our incidence numbers are similar to previous reports from the general population..$^{411,37,38}$ However, symptomatic symptoms can occur after 5 minutes, depending on autonomic response and those being characterized as nonorthostatic in other studies. Any misread of blood pressure by the physician would merely introduce a non-differential misclassification. Finally, the group of people that suffers from the symptoms of $\mathrm{OH}$ seems to be at risk of developing cognitive deficiencies, despite the fact that they do not qualify for $\mathrm{OH}$. A fall of greater than $20 \mathrm{mmHg}$ in SBP or greater than $10 \mathrm{mmHg}$ in DBP might therefore be questioned when analyzing associations to cognitive decline, since they could introduce misclassification for subjects with less blood pressure fall using peripheral (brachial) blood pressure for screening of $\mathrm{OH}$. In this study, the guidelines used for initial $\mathrm{OH}$ were according to the European Society of Cardiology. ${ }^{39}$ The rationale for higher cut-off levels to define $\mathrm{OH}$ immediately after standing up, ie, falls of $>40 \mathrm{mmHg}$ for SBP and $>20 \mathrm{mmHg}$ for DBP, is the rapid hemodynamic changes of vascular resistance, heart rate, and rebound effects during the first half-minute. ${ }^{40}$ However, the noted increase of $\mathrm{OH}$ after about 75 years of age might be explained by atherosclerotic changes and autonomic dysfunction. On the other hand, it could be speculated on the need of age-related cut-off limits of $\mathrm{OH}$ to reduce possible detection bias.

In this study, we chose three-word recollection from the $\mathrm{MMSE}^{15}$ as an indicator of memory and learning, and aMCI. In an extensive review, Tombaugh and McIntyre reported moderate-to-high test-retest reliability, citing correlations of 0.38 to 0.99 in studies of MMSE, and corresponding values for internal consistency as expressed by Cronbach's alpha coefficients in the order of 0.54 to 0.96 . Studies on concurrent validity have reported correlation coefficients ranging from 0.70 to 0.90 between MMSE and other measures of cognitive impairment. ${ }^{41}$ The sensitivity of the three-word recall was reported to be 0.65 and the specificity 0.85 by Kuslansky et al. ${ }^{42}$ aMCI has been associated with progression to Alzheimer's disease, and it could be argued that the lack of association with SBP or DBP falls in this study might have been captured by assessing other cognitive domains and naMCI associated with vascular dementia and normal aging. ${ }^{38}$ We intend to explore this approach in forthcoming analyses. Classification of subtypes of dementia would have increased understanding of possible pathological mechanisms behind our findings. The aMCI criteria according to Petersen et al include largely intact ADL. ${ }^{24}$ In this study, subjects with disabilities and impaired ADL were not excluded, but very few subjects had impaired ADL of personal functions, and no differences regarding ADL were noted between groups. Thus, it is not likely that this would have influenced the noted associaitons between $\mathrm{OH}$ reactions and reported incidence of MCI. Furthermore, subjects with an MMSE score below 24 at baseline were excluded in order to reduce the possibility of including subjects with dementia. The exclusion of subjects with stroke and cardiovascular disease at baseline might introduce some underestimation of incident MCI, since this group has a higher load of vascular risk factors. On the other hand, both these conditions are possible confounding factors that can affect both cognition and the risk for $\mathrm{OH}$, which could introduce false risk associations despite the longitudinal design. Education and age are well-known confounders for MCI and were controlled for in analyses.

As expected, hypertension or treatment for hypertension was related to a higher proportion of $\mathrm{OH}$, and the proportion of $\mathrm{OH}$ in incident cases of MCI and dementia was almost double compared to non-hypertensive subjects. However, the association of orthostatic symptoms to MCI, irrespective of blood pressure fall, remained in the non-hypertensive group, indicating that insufficient cerebral autoregulation is not only mediated through hypertension-induced atherosclerosis or antihypertensive drug adverse events with peripheral hypotension. ${ }^{9}$

A previous review on MCI by Ward et al in 2012 reported 13 studies, but only five studies presented age-stratified rates. ${ }^{43}$ Two of these studies ${ }^{44,45}$ observed significant increases of MCI with age, from 3.7 to 46.6 per 1,000 py and from 5.3 to 16.3 per 1,000 py, respectively, in those aged 65 to 85 years of age. Different operational definitions of diagnostic criteria might explain the differences in published estimates of MCI. Furthermore, the study by Solfrizzi et al in some cases applied the criteria of subjective memory complaints retroactively, since the study did not require subjective memory impairment. ${ }^{44}$ Another systematic review of incident MCI identified nine studies in which incidence of aMCI subtypes ranged between 9.9 and 40.6 per 1,000 py, which was similar to our findings. ${ }^{46}$ The incidence of naMCI subtypes ranged from 28 to 36.3 per 1,000 py, but no age-stratified data were presented. ${ }^{46}$ Roberts et al estimated the incidence of aMCI in men and women separately and found a higher incidence for men (43.9/1,000 py) than for women $(33.3 / 1,000 \mathrm{py}),{ }^{13}$ which was also a finding of the present study. The difference between men and women in incidence rate of MCI declined with higher education, but 
a difference was observed regardless of whether the length of education was more or less than 12 years. These reported incidence studies represent only a part of all cognitive deficits categorized as MCI. To summarize, this study and previous similar studies do not support the finding that age-adjusted MCI incidence decreases, although the birth cohort effects of higher education should be taken account in forthcoming longitudinal studies. ${ }^{18}$

Our data on incidence of dementia for the age groups 60 to 69 and 70 to 79 years are higher than those of a recent study from Rotterdam, the Netherlands that indicated a decreasing incidence over the preceding decade. ${ }^{16}$ However, our data are comparable to those of a study by Letenneur et al which comprised similar age groups and reported an overall incidence of dementia of 16.3/1,000 py, compared to $13.9 / 1,000$ py in the present study. ${ }^{47}$

This is, to our knowledge, the first longitudinal study on the relationships between $\mathrm{OH}$, orthostatic symptoms, and the development of MCI. The same standardized protocol was used at baseline and at follow-up, and the study population was randomized from the general population and not restricted to any disorder, sex, ethnicity, or education, which increases generalization. Home visits were offered to those unable to attend the research center to reduce selection bias of more frail subjects. A higher proportion of disabled subjects among nonparticipants cannot be ruled out, but the 6-year-long follow-up would have reduced the effects of this on incidence estimates. We have no reason to believe that depressive mood at follow-up confounded the results.

\section{Conclusion}

$\mathrm{OH}$ and symptoms of $\mathrm{OH}$ in the elderly general population seem to be risk factors for cerebral hypoxic damage and incident MCI, probably due to disturbed cerebral autoregulation. This should be considered in medical treatment, especially that of blood pressure.

\section{Acknowledgments}

The Good Aging in Skåne (GÅS-SNAC) project, part of the Swedish National Study on Aging and Care, was supported by the Swedish Ministry of Health and Social Affairs, the county Region Skåne, the Medical Faculty at Lund University, and the Swedish Research Council (grant number 2013-8604).

\section{Disclosure}

The authors report no conflicts of interest in this work.

\section{References}

1. Rose KM, Couper D, Eigenbrodt ML, Mosley TH, Sharrett AR, Gottesman RF. Orthostatic hypotension and cognitive function: the Atherosclerosis Risk in Communities Study. Neuroepidemiology. 2010; 34(1):1-7.

2. Schoon Y, Lagro J, Verhoeven Y, Rikkert MO, Claassen J. Hypotensive syndromes are not associated with cognitive impairment in geriatric patients. Am J Alzheimers Dis Other Demen. 2013;28(1):47-53.

3. Allan LM, Ballard CG, Allen J, et al. Autonomic dysfunction in dementia. J Neurol Neurosurg Psychiatry. 2007;78(7):671-677.

4. Mehrabian S, Duron E, Labouree F, et al. Relationship between orthostatic hypotension and cognitive impairment in the elderly. J Neurol Sci. 2010;299(1-2):45-48.

5. Elmstáhl S, Rosén I. Postural hypotension and EEG variables predict cognitive decline: results from a 5-year follow-up of healthy elderly women. Dement Geriatr Cogn Disord. 1997;8(3):180-187.

6. Perlmuter LC, Sarda G, Casavant V, et al. A review of orthostatic blood pressure regulation and its association with mood and cognition. Clin Auton Res. 2012;22(2):99-107.

7. Rutan GH, Hermanson B, Bild DE, Kittner SJ, LaBaw F, Tell GS. Orthostatic hypotension in older adults. The Cardiovascular Health Study. CHS Collaborative Research Group. Hypertension 1992;19:508-519.

8. Novak V, Hajjar I. The relationship between blood pressure and cognitive function. Nat Rev Cardiol. 2010;7(12):686-698.

9. Moretti R, Torre P, Antonello RM, Manganaro D, Vilotti C, Pizzolato G. Risk factors for vascular dementia: hypotension as a key point. Vasc Health Risk Manag. 2008;4(2):395-402.

10. Qiu C, Winblad B, Fratiglioni L. The age-dependent relation of blood pressure to cognitive function and dementia. Lancet Neurol. 2005;4(8): 487-499.

11. Siennicki-Lantz A, Lilja B, Elmståhl S. Orthostatic hypotension in Alzheimer's disease: result or cause of brain dysfunction? Aging (Milano). 1999;11(3):155-160.

12. Furuäng L, Siennicki-Lantz A, Elmståhl S. Reduced cerebral perfusion in elderly men with silent myocardial ischaemia and nocturnal blood pressure dipping. Atherosclerosis. 2011;214(1):231-236.

13. Roberts RO, Geda YE, Knopman DS, et al. The incidence of MCI differs by subtype and is higher in men: the Mayo Clinic Study of Aging. Neurology. 2012;78(5):342-351.

14. Eckerström C, Olsson E, Borga M, et al. Small baseline volume of left hippocampus is associated with subsequent conversion of MCI into dementia: the Göteborg MCI study. J Neurol Sci. 2008;272(1-2): $48-59$.

15. Folstein MF, Folstein SE, McHugh PR. "Mini-mental state". A practical method for grading the cognitive state of patients for the clinician J Psychiatr Res. 1975;12(3):189-198.

16. Schrijvers EM, Verhaaren BF, Koudstaal PJ, Hofman A, Ikram MA, Breteler MM. Is dementia incidence declining?: Trends in dementia incidence since 1990 in the Rotterdam Study. Neurology. 2012;78(19): $1456-1463$.

17. Qiu C, von Strauss E, Bäckman L, Winblad B, Fratiglioni L. Twentyyear changes in dementia occurrence suggest decreasing incidence in central Stockholm, Sweden. Neurology. 2013;80(20):1888-1894.

18. Rocca W, Petersen R, Knopman D, et al. Trends in the incidence and prevalence of Alzheimers's disease, dementia, and cognitive impairment in the United States. Alzheimers Dement. 2011;7(1):80-93.

19. Ekström H, Elmståhl S. Pain and fractures are independently related to lower walking speed and grip strength: results from the population study "Good Ageing in Skåne”. Acta Orthop. 2006;77(6):902-911.

20. Lagergren M, Fratiglioni L, Hallberg IR, et al. A longitudinal study integrating population, care and social services data. The Swedish National study on Aging and Care (SNAC). Aging Clin Exp Res. 2004;16(2):158-168.

21. American Psychiatric Association, American Psychiatric Association. Task Force on DSM-IV. Diagnostic and Statistical Manual of Mental Disorders: DSM-IV-TR. 4th ed. Washington, DC: American Psychiatric Association; 2000. 
22. World Health Organization. International Statistical Classification of Diseases and Related Health Problems. 10th revision, 2nd ed. Geneva: World Health Organization; 2004.

23. Structures and Principles [webpage on the Internet]. Oslo: WHO Collaborating Centre for Drug Statistics Methodology; 2012 [updated March 25, 2011]. Available from: http://www.whocc.no/atc/structure_and_principles. Accessed August 1, 2013.

24. Petersen RC, Smith GE, Waring SC, Ivnik RJ, Tangalos EG, Kokmen E. Mild cognitive impairment: clinical characterization and outcome. Arch Neurol. 1999;56(3):303-308.

25. Crook TH, Bartus RT, Ferris SH, Whitehouse P, Cohen GD, Gershon S. Age-associated memory impairment: proposed diagnostic criteria and measures of clinical change - report of a National Institute of Mental Health work group. Dev Neuropsychol. 1986;2:261-276.

26. Asberg KH, Sonn U. The cumulative structure of personal and instrumental ADL. A study of elderly people in a health service district. Scand J Rehabil Med. 1989;21(4):171-177.

27. Montgomery SA, Asberg M. A new depression scale designed to be sensitive to change. Br J Psychiatry. 1979;134:382-389.

28. Czajkowska J, Ozhog S, Smith E, Perlmuter LC. Cognition and hopelessness in association with subsyndromal orthostatic hypotension. J Gerontol A Biol Sci Med Sci. 2010;65(8):873-879.

29. Collins O, Dillon S, Finucane C, Lawlor B, Kenny RA. Parasympathetic autonomic dysfunction is common in mild cognitive impairment. Neurobiol Aging. 2012;33(10):2324-2333.

30. Axelsson J, Reinprecht F, Siennicki-Lantz A, Elmståhl S. Lower cognitive performance in 81-year-old men with greater nocturnal blood pressure dipping. Int J Gen Med. 2008;1:69-75.

31. Romero-Ortuno R, Cogan L, Fan CW, Kenny RA. Intolerance to initial orthostasis relates to systolic BP changes in elders. Clin Auton Res. 2010;20(1):39-45.

32. van Osch MJ, Jansen PA, Vingerhoets RW, van der Grond J. Association between supine cerebral perfusion and symptomatic orthostatic hypotension. Neuroimage. 2005;27(4):789-794.

33. Elias MF, Wolf PA, D’Agostino RB, Cobb J, White LR. Untreated blood pressure level is inversely related to cognitive functioning: the Framingham Study. Am J Epidemiol. 1993;138:353-364.

34. Swan GE, Carmelli D, Larue A. Systolic blood pressure tracking over 25 to 30 years and cognitive performance in older adults. Stroke. 1998; 29(11):2334-2340.

35. Siennicki-Lantz A, Lilja B, Rosén I, Elmståhl S. Cerebral blood flow in white matter is correlated with systolic blood pressure and EEG in senile dementia of the Alzheimer type. Dement Geriatr Cogn Disord. 1998;9(1):29-38.
36. Gangavati A, Hajjar I, Quach L, et al. Hypertension, orthostatic hypotension, and the risk of falls in a community-dwelling elderly population: the maintenance of balance, independent living, intellect, and zest in the elderly of Boston study. J Am Geriatr Soc. 2011;59(3):383-389.

37. Rockwood MR, Howlett SE, Rockwood K. Orthostatic hypotension $(\mathrm{OH})$ and mortality in relation to age, blood pressure and frailty. Arch Gerontol Geriatr. 2012;54(3):e255-e260.

38. Petersen RC, Doody R, Kurz A, et al. Current concepts in mild cognitive impairment. Arch Neurol. 2001;58(12):1985-1992.

39. Task Force for the Diagnosis and Management of Syncope; European Society of Cardiology (ESC); European Heart Rhythm Association (EHRA), et al. Guidelines for the diagnosis and management of syncope (version 2009). Eur Heart J. 2009;30(21):2631-2671.

40. Smith JJ, Porth CM, Erickson M. Hemodynamic response to the upright posture. J Clin Pharmacol. 1994;34:375-386.

41. Tombaugh TN, McIntyre NJ. The mini-mental state examination: a comprehensive review. J Am Geriatr Soc. 1992;40:922-935.

42. Kuslansky G, Buschke H, Katz M, Sliwinski M, Lipton RB. Screening for Alzheimer's disease: the memory impairment screen versus the conventional three-word memory test. J Am Geriatr Soc. 2002;50(6): 1086-1091.

43. Ward A, Arrighi M, Michels S, Cedarbaum J. Mild cognitive impairment: disparity of incidence and prevalence estimates. Alzheimers Dement. 2012;8:14-21.

44. Solfrizzi V, Panza F, Colacicco AM, et al; Italian Longitudinal Study on Aging Working Group. Vascular risk factors, incidence of MCI, and rates of progression to dementia. Neurology. 2004;63:1882-1891.

45. Caracciolo B, Palmer K, Monastero R, Winblad B, Bäckman L, Fratiglioni L. Occurrence of cognitive impairment and dementia in the community: a 9-year-long prospective study. Neurology. 2008;70: 1778-1785

46. Luck T, Luppa M, Briel S, Riedel-Heller SG. Incidence of mild cognitive impairment: a systematic review. Dement Geriatr Cogn Disord. 2010;29(2):164-175.

47. Letenneur L, Commenges D, Dartigues JF, Barberger-Gateau P. Incidence of dementia and Alzheimer's disease in elderly community residents of south-western France. Int J Epidemiol. 1994;23(6): $1256-1261$.
Clinical Interventions in Aging

\section{Publish your work in this journal}

Clinical Interventions in Aging is an international, peer-reviewed journal focusing on evidence-based reports on the value or lack thereof of treatments intended to prevent or delay the onset of maladaptive correlates of aging in human beings. This journal is indexed on PubMed Central, MedLine,

\section{Dovepress}

CAS, Scopus and the Elsevier Bibliographic databases. The manuscript management system is completely online and includes a very quick and fair peer-review system, which is all easy to use. Visit http://www.dovepress. com/testimonials.php to read real quotes from published authors. 